\title{
Conducting a microscopic analysis of the powders obtained by electroerosion dispersion of waste of steel X13
}

\author{
E.V. Ageeva ${ }^{1}, S . V$. Khardikov $^{2 *}$, and $A . N$. Novikov $^{3}$ \\ ${ }^{1}$ Southwest state University, 305040, Kursk, Russian Federation \\ ${ }^{2}$ Southwest state University, 305040, Kursk, Russian Federation \\ ${ }^{3}$ OSU named after I. S. Turgenev, 302026, Orel, Russian Federation
}

\begin{abstract}
Alloyed steels and alloys containing a significant amount of non-ferrous metals are used for the manufacture of critical parts for various purposes, since it is the alloyed steels and alloys that possess a complex of high physicomechanical and other properties. Chromium is the most common alloying element. Chromium alloyed steel has increased strength, hardness, wear resistance, corrosion resistance in aggressive and oxidizing environments. The presence of chromium increases the hardenability of steel. The process of obtaining powder materials by the method of electroerosion dispersion favorably differs by the possibility of obtaining powders even from very hard and refractory materials. In the case of grinding material with this method, the only important criterion is the electrical conductivity of the material being ground. Worn parts and other scrap can be used as feedstock during the process. The purpose of the study is to investigate the powder, obtained from the wastes of chromiumcontaining steels. Thanks to the study of the samples of the used powder, on modern devices, results were obtained, indicating that the chromiumcontaining powder, obtained by the method of electroerosive dispersion, can be reused to restore and strengthen machine parts.
\end{abstract}

\section{Introduction}

Powder technology is a broad area for the production of dispersed bodies, used in various branches of production - powder metallurgy, the ceramic industry, the production of food and medicinal products, fertilizers, fuel, building materials, etc. Due to some external similarity of the technology of powder metallurgy with the technology of ceramic production, products manufactured by powder metallurgy are also widely known as metalceramic [1-3].

Along with the advantages of powder metallurgy, it should be noted that there are disadvantages that impede and limit its wide distribution. The main disadvantages include the high cost of metal powders and the lack of mastered methods for producing alloy powders - steels, bronzes, brass, etc. One of the solutions to these problems is the use of

\footnotetext{
* Corresponding author: hardikov1990@mail.ru
} 
electric erosion. Currently, alloyed steels and alloys containing a significant amount of nonferrous metals are used for the manufacture of critical parts for various purposes, since it is the alloyed steels and alloys that possess a complex of high physicomechanical and other properties.

Carbon steels do not have sufficiently high mechanical and physicochemical properties and do not meet the requirements for metals in modern engineering. One of the main ways to improve the properties of steel is the introduction of various elements into it. The process of introducing various elements into steel to enhance its properties is called alloying, and the resulting steels are called alloyed [4-6]

The introduction of alloying elements leads to the formation of new phases and structural components, changes the kinetics of transformations, causes new phenomena and changes the technology of heat treatment. The alloying elements introduced into carbon steel, change its mechanical and physical properties. Doping significantly increases the strength and hardness while maintaining good toughness of steel, increases its hardenability, allows for quenching in moderate coolers. Doping gives the steels a number of special properties: heat resistance, corrosion resistance, scaling resistance, magnetoresistance and many other properties.

Chromium is the most common alloying element. Chromium alloyed steel has increased strength, hardness, wear resistance, corrosion resistance in aggressive and oxidizing environments. The presence of chromium increases the hardenability of steel. With $13 \%$ chromium in steel, it becomes stainless. A further increase in the chromium content gives the steel anti-corrosion at high temperatures, as well as magnetoresistance.

Due to the widespread use of chromium-containing steels in industry, there is currently an acute problem of recycling their waste. The most promising method of processing such wastes is the electro-erosion dispersion method (EED), which is distinguished by the ecological purity of the process and relatively low energy costs [7-9].

For the development of technologies for the practical application of powder, obtained from wastes, and evaluating the effectiveness of its use, complex theoretical and experimental studies are required.

The aim of the work was to study the particle size distribution of the powder particles, obtained by electro-erosion dispersion of chromium-containing wastes in lighting kerosene.

\section{Materials and methods}

To carry out the planned researches, chromium-containing steel wastes were selected. Lighting kerosene was chosen as a working fluid. To obtain a powder by the method of electroerosive dispersion, an installation for EED of conductive materials was used. Wastes were loaded into a reactor filled with a working fluid - lighting kerosene; the process was carried out with the following electrical parameters: discharge capacitor capacity $45 \mu \mathrm{F}$, voltage $100 \ldots 110 \mathrm{~V}$, pulse repetition rate $55 \ldots 65 \mathrm{~Hz}$. As a result of the local impact of short-term electrical discharges between the electrodes, the waste material was destroyed with the formation of dispersed powder particles.

Using the QUANTA 600 FEG scanning electron microscope, a direct analysis of powder particles with a sufficiently high resolution was carried out. The QUANTA 600 FEG - (manufactured by FEI (Holland)) is an electron-ion scanning microscope with an electron beam column equipped with a tungsten cathode. Its accelerating voltage is from $200 \mathrm{eV}$ to $30 \mathrm{kV}$ and its resolution is $3.5 \mathrm{~nm}$ at $35 \mathrm{kV}$ at optimum $\mathrm{WD}, 3.5 \mathrm{~nm}$ at $30 \mathrm{kV}$ in natural mode and less than $15 \mathrm{~nm}$ at $1 \mathrm{kV}$ in low vacuum mode. The ion column with a gallium liquid-metal ion source Magnum has an accelerating voltage of $5 \mathrm{kV}$ to $30 \mathrm{kV}$ and a resolution of $20 \mathrm{~nm}$. The system is equipped with a five axial motorized $50 \times 50 \times 25 \mathrm{~mm}$ 
table, gas injection systems for spraying conductors and dielectrics, as well as for etching samples.

Powders obtained from electro-erosion dispersion in kerosene from chrome-containing steel wastes were analyzed using an Analysette 22 NanoTec laser particle size analyzer to determine the size distribution of the obtained powder particles.

\section{The study of the microstructure of powders}

Using the method of scanning electron microscopy (SEM), particles of a powder sample were investigated using a secondary electron detector (Fig. 1).

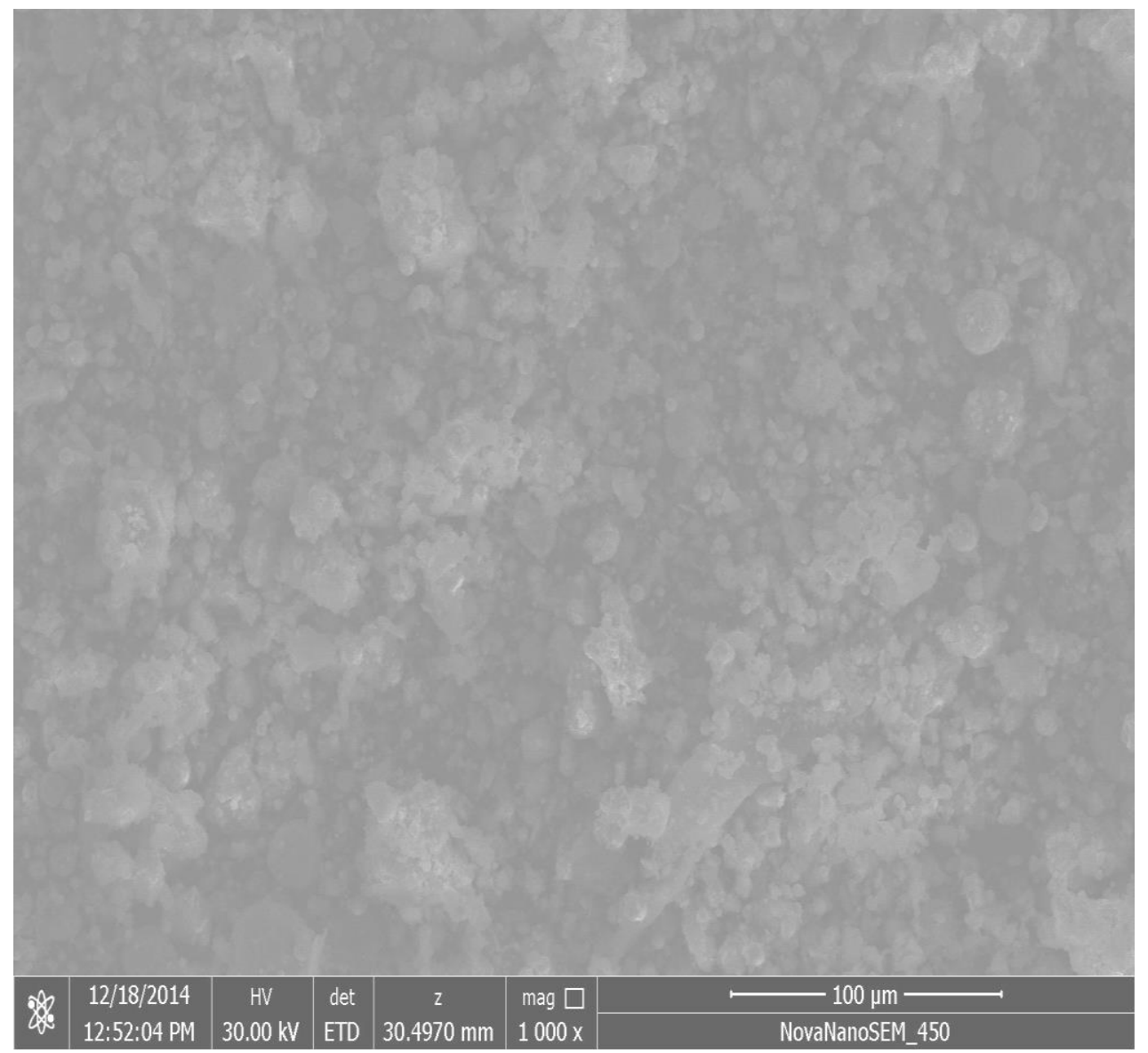

Fig. 1. Photograph of powder particles, obtained by EED

It can be seen that the shape of the powder particles is determined by the form in which the material is ejected from the well in the EED process. It is also seen that particles with a regular spherical or elliptical shape prevail in the powder. They are obtained by crystallization of the molten material (liquid phase). Particles formed during the crystallization of a boiling material (vapor phase) have an irregular shape, an order of magnitude smaller than particles formed from the liquid phase, and usually agglomerate with each other and on the surface of other particles. In the process of EED such particles are most susceptible to chemical and phase changes. 

1 .

The results of measuring the particle size of the obtained powder are presented in Figure

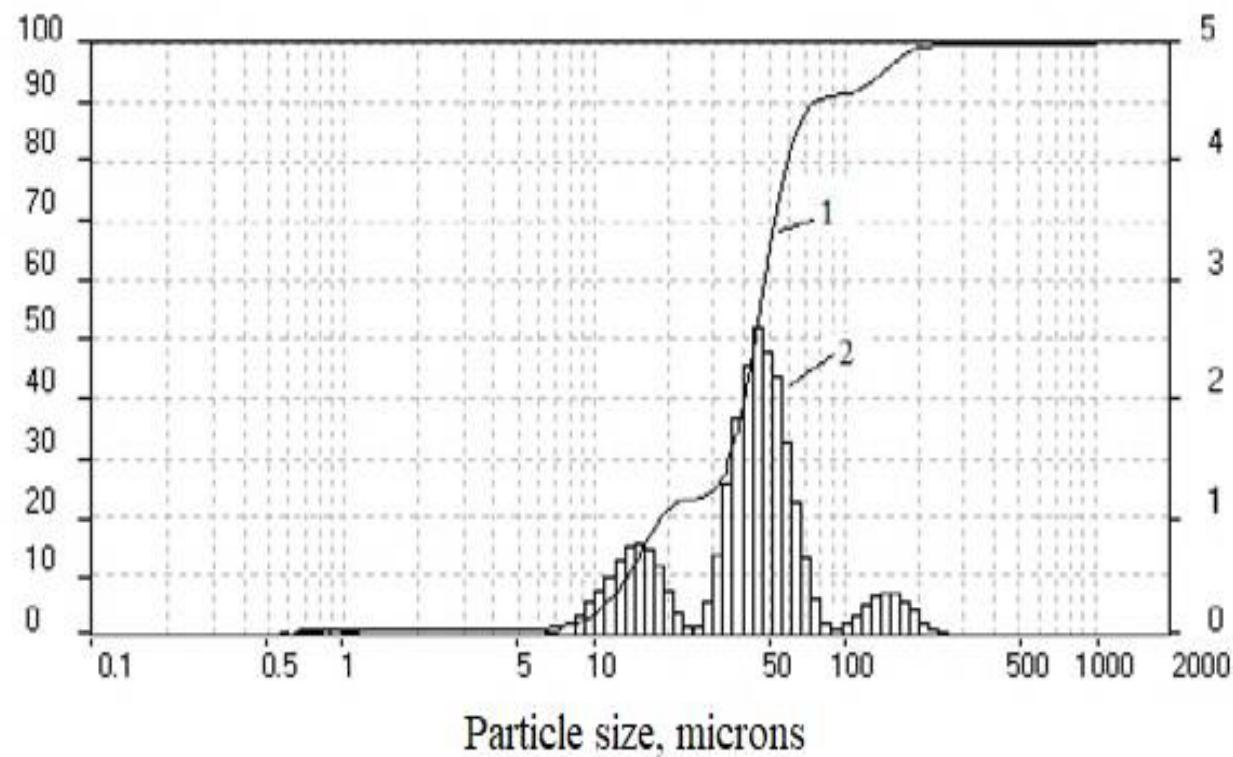

Fig. 2. The size distribution of powder microparticles: 1 - Integral curve, 2 - Histogram.

It was established that the average particle size is $49.33 \mu \mathrm{m}$, the arithmetic value is $49.328 \mu \mathrm{m}$, and the specific surface area is $2732.76 \mathrm{~cm}^{2} / \mathrm{cm}^{3}$.

\section{Conclusion}

In the course of the experimental research aimed at the study of the particle size of the chromium powder, which was obtained by electroerosion dispersion of wastes in lighting kerosene with the following electrical parameters: the capacity of the discharge capacitors is $45 \mu \mathrm{F}$, the voltage is from $100 \mathrm{~V}$ to $110 \mathrm{~V}$, the pulse frequency is from $55 \mathrm{~Hz}$ to $65 \mathrm{~Hz}$, the average particle size and the specific surface area were determined. It allows to identify the rational area of its practical application.

On the basis of the obtained results, it can be concluded that the chromium powder, obtained by the method of electroerosive dispersion, can be reused when restoring and hardening machine parts.

The work was supported by a scholarship of the President of the Russian Federation to young scientists and graduate students (SP-945.2019.1).

\section{References}

1. Mal'tsev I.M.,. International Science and Technology Magazine (2003)

2. Chandler K.M., Mitchell M.D., Pikuz S.A., Shelkovenko T.A., Hammer D.A., Shlyaptseva A.S., Ouart N.D., Hansen S.B., Kantsyrev V.L., Fedin D.A. Rev. Sci. Instrum. 75, 10-2, 3702. (2004)

3. Wang Z., Qiu K. Electrochem. Commun. 8 (7), 1075. (2006)

4. Wang Z., Gao G., Zhu H., Sun Z., Liu H., Zhao X., Int. J. Hydrogen. Energ. 34 (23), 9334 (2009) 
5. Kazi I.H., Wild P.M., Moore T.N., Sayer M. Thin Solid Films. 515 (4), 2602 (2006)

6. Chen T.J., Lee R.T., Chiou Y.C. Proceedings of the Institution of Mechanical Engineers, Part B: Journal of Engineering Manufacture. T. 227 (11), 1596-1606. (2013)

7. Huang Y., Wu H., Shao T., Zhao X., Peng H., Gong Y., Wan H. Chemical Engineering Journal. T. 339. 322-333. (2018)

8. Sassi W., Dhouibi L., Triki E., Berçot P., Rezrazi M. Electrochimica Acta. T. 117, 43452. (2014)

9. Ageeva E.V., Ageev E.V., Horyakova N.M. Russ. Eng. Res. 35 (1), 33. (2015) 